\title{
Psychosomatic Primary Care in Gynecology-Assessment and Acceptance by Residents for Obstetrics and Gynecology in Germany
}

\author{
„Psychosomatische Grundversorgung“ in der Frauenheilkunde - Bewertung, Akzeptanz und Beurteilung \\ von Assistenten für Frauenheilkunde und Geburtshilfe in Deutschland
}

Authors

Affiliations
S. Schott ${ }^{1,6}$, J. Lermann ${ }^{2,6}$, M. Rauchfuß3 ${ }^{3,7}$, O. Ortmann ${ }^{4,6,8}$, S. Ditz ${ }^{5,7}$

The affiliations are listed at the end of the article.

\section{Key words \\ - gynecology \\ - continued training \\ Schlüsselwörter \\ - Frauenheilkunde \\ - Gynäkologie \\ - Psychosomatik \\ - Weiterbildung \\ - Facharzt}

- psychosomatic medicine

- specialist medical training

Deutschsprachige Zusatzinformationen online abrufbar unter: www.thieme-connect.de/ ejournals/toc/gebfra

\section{received $\quad 15.12 .2013$ \\ revised $\quad 2.4 .2014$ \\ accepted 20.4.2014}

Bibliography

DOI http://dx.doi.org/

10.1055/s-0034-1368513

Geburtsh Frauenheilk 2014; 74 :

569-573 @ Georg Thieme

Verlag KG Stuttgart · New York ISSN 0016-5751

\section{Correspondence}

\section{Dr. Sarah Schott}

Universitätsklinikum Heidelberg

Universitätsfrauenklinik

Im Neuenheimer Feld 440

69120 Heidelberg

Sarah.Schott@

med.uni-heidelberg.de

\section{Abstract \\ $\nabla$}

Background: The course "Psychosomatic Primary Care" has been part of the training curriculum of obstetrics and gynecology in Germany since 2003. The aim of the course is to train up physicians, whose prior training primarily focussed on somatic care, to enable them to offer care also taking into account biopsychosocial aspects. Taking the guidelines for psychotherapy as a template, the aim of psychosomatic primary care is to recognize the etiological links between psychological and somatic factors which contribute to diseases. The necessity for a compulsory course as part of training in gynecology was recently critically discussed. Major points discussed included the question whether the current forms of teaching, consisting of courses, are outdated and whether the required skills should be part of regular daily training.

Method: A 3-part online questionnaire consisting of 30 items was developed and sent to 2431 residents in the period from September to December 2012 through the online mailing list of the DGGG. Results: The 540 residents who responded to the questionnaire were predominantly female (83.3\%) with an average age of 30 years; $50.3 \%$ were in their 1 st to their 4 th year of training. Over the longer term, the majority of respondents (56.1\%) hoped to continue working in a hospital and regularly (84.6\%) attended teaching courses voluntarily. $70.9 \%$ of them had already attended the course "Psychosomatic Primary Care". Of the group who had completed the course, $29.4 \%$ were satisfied with the offer. The main criticism directed against the course was its scope which $24.1 \%$ considered completely inadequate. $24.5 \%$ considered the course to be an important part of training, while $16.5 \%$ would have preferred that the course be abolished. $18 \%$ of respondents reported that psychosomatic medicine did not feature regularly in their daily clinical routine.

\section{Zusammenfassung \\ $\nabla$}

Hintergrund: Der Grundkurs „Psychosomatische Grundversorgung“ ist seit 2003 in der Musterweiterbildungsordnung zum Facharzt für Frauenheilkunde und Geburtshilfe vorgeschrieben. Ziel des Kurses ist es, primär somatisch orientierte Ärztinnen und Ärzte zu einer biopsychosozial orientierten Versorgung und Betreuung der Patientinnen zu befähigen. Im Rahmen der psychosomatischen Grundversorgung sollen nach den Psychotherapierichtlinien ätiologische Verknüpfungen psychischer und somatischer Krankheitsfaktoren erkannt und in ihrer pathogenen Bedeutung gewichtet werden. In jüngster Vergangenheit wurde die Notwendigkeit eines verpflichtenden Kurses im Rahmen der Gebietsweiterbildung kritisch diskutiert. Zentrale Diskussionspunkte waren, ob die Wissensvermittlung in den angebotenen, meist teuren Kursformen noch zeitgemäß sei oder ob die notwendigen Fertigkeiten Bestandteil des Weiterbildungsalltags sein sollten.

Methode: Es wurde ein 3-teiliger Onlinefragebogen mit 30 Items entwickelt, der im Zeitraum von 9 bis 12/2012 an 2431 Assistenzärzte über den Onlineverteiler der DGGG gesandt wurde.

Ergebnisse: Die 540 Assistenzärzte, die an der Befragung teilnahmen, waren überwiegend weiblich $(83,3 \%)$, durchschnittlich 30 Jahre alt und zu 50,3\% im 1.-4. Weiterbildungsjahr tätig. Die Mehrzahl der Befragten (56,1\%) strebten langfristig eine Kliniktätigkeit an und besuchten $(84,6 \%)$ regelmäßig kostenpflichtige Kurse. 70,9\% hatten bereits Erfahrungen mit dem Kurs „Psychosomatische Grundversorgung“. 29,4\% von diesen waren mit dem Kursangebot zufrieden. Vor allem kritisiert wurde der Umfang des Kurses, der von $24,1 \%$ als überhaupt nicht angemessen bewertet wurde. 24,5\% erachteten den Kurs als wichtigen Bestandteil der Facharztausbildung, wohingegen $16,5 \%$ wünschten, diesen Kurs zu streichen. 18\% der Befragten gaben an, dass die 
Perspective: Because of the huge gap between what is currently offered and the experiences reported by the respondents, the Young Forum of the DGGG and the DGPFG have expanded the program of courses offered by the DGPFG, which will offer practice-oriented courses to future gynecologists across Germany in cooperation with the DAGG. The first courses are held in Heidelberg and Erlangen in 2014.

\section{Introduction}

$\nabla$

The physician's ability to offer professional advice and care which focusses on their patients' needs is central to gynecology.

Psychosomatic primary care is an integral part of the daily work of gynecologists; it means being able to recognize psychogenic disorders, to assess psychosocial factors in physical disease, to offer patient-centered advice and care, and to pilot patients through the system of psychosocial care. In addition to helpful discussion techniques, the key element to generate a satisfying and successful discussion is a physician's conscious attitude towards psychosomatic disease.

Suboptimal communication can have clinically relevant consequences for patients. Clinically significant psychological stresses and physical symptoms are often inadequately diagnosed and may remain untreated. This is highly relevant, as $20-30 \%$ of patients who visit GPs' suffer from psychogenic or secondary psychosomatic disorders [1].

When the Regulations on the Licensing of Medical Practitioners were amended in 1972, psychosomatic medicine and psychotherapy were integrated into medical training and are therefore a mandatory subject for every prospective physician. The course "Psychosomatic Primary Care" has been part of the training curriculum for specialists in gynecology and obstetrics since 2003 and is required of all physicians wanting to become gynecologists. The required coursework corresponds approximately to that required for services billed as EBM Nos. 35100 and 35110 [2]. The training course consists of theory seminars (20 hours), communicating and practicing verbal intervention techniques (30 hours), and work in Balint groups (30 hours).

The aim of the course is to train up physicians beyond their skills on somatic medicine, so that they can offer their patients care which takes greater account of biopsychosocial aspects [3]; the goal is to enable them to make a differential diagnosis of a complex clinical picture as early as possible [4]. According to current studies, the learning process involved extends over a period of 35 years [1].

The necessity for a mandatory course as part of specialist training in gynecology has led to a critical discussion recently. The major points discussed at the time included the questions whether the current forms of instruction in the shape of courses paid for by the trainees are outdated and whether the required skills should be part of regular specialist training to allow trainees to recognize and treat psychosomatic illnesses in their daily gynecological practice $[5,6]$. The discussion between representatives of the German Society for Psychosomatic Gynecology and Obstetrics (Deutsche Gesellschaft für Psychosomatische Frauenheilkunde und Geburtshilfe e.V. [DGPFG]) and the Young Forum of the German Society for Gynecology and Obstetrics (Deutsche Gesellschaft für Gynäkologie und Geburtshilfe e.V. [DGGG]) resulted in a joint survey of all members of the DGGG in training. The aim of the survey was to evaluate trainees' experiences of the course
Psychosomatik kein fester Bestandteil ihres klinischen Arbeitsalltags sei.

Ausblick: Aufgrund der hohen Diskrepanz der Angebote und der Erfahrungen der Befragten, haben das Junge Forum der DGGG und die DGPFG das Kursprogramm der DGPFG erweitert, das kostengünstige, praxisrelevante Kurse für zukünftige Frauenärzte deutschlandweit in Kooperation mit der DAGG anbieten wird. Erste Kurse werden in Heidelberg und Erlangen 2014 angeboten.

"Psychosomatic Primary Care", particularly with respect to the level of its acceptance. In addition, the study aimed to draw attention to concerns voiced by residents and use the results of the survey to improve psychosomatic primary care courses for gynecologists and obstetricians in respect to their special requirements offering a great personal benefit to trainees.

The results of the internet survey are outlined and discussed below. The proposals for the training course on psychosomatic primary care put forward by the DGPFG and the Young Forum of the DGGG together with the German Academy for Gynecology and Obstetrics (Deutsche Akademie für Gynäkologie und Geburtshilfe [DAGG]) are presented here.

\section{Methods}

$\nabla$

A 3-part questionnaire with 30 items was developed. The 1st part consisted of 7 questions for the collection of demographical data; the 2 nd part included 14 questions which evaluated the respondent's attitude towards and experience with psychosomatic primary care ( Fig. 1). Unless otherwise specified, evaluation was done using a scale from 1 to 6 , with 1 as the best score and 6 as the worst score (very satisfied - entirely dissatisfied; very important - entirely unimportant). Scores between 1 and 3 were evaluated as broadly favorable.

The 3rd part asked the respondent's opinion of a new training concept for outpatient care which was developed in collaboration with the Professional Association of Gynecologists (Berufsverband der Frauenärzte, currently still in press). The last question left space for respondents to add their own comments.

The anonymous online questionnaire was distributed 3 times over the period from September to December 2012 via the Newsletter of the Young Forum of the DGGG 3. According to information provided by the office of the DGGG, the Newsletter reaches 2431 members in training. Data collection and evaluation was done using www.surveymonkey.de.

\section{Results \\ $\nabla$}

Demographic data, work experience and career objectives of respondents

A total of 504 (20.7\%) persons sent the questionnaire filled in the online survey evaluating the "Psychosomatic Primary Care". The overwhelming majority of respondents were female (83.3\%), and the average age of the residents who responded was 30 years (25-52 range); $46.9 \%$ of respondents were in their 1 st to 4 th year of gynecology training. Around one quarter of respondents was in their 5th year of training (22\%) or already working as a trained specialist (21.5\%). At the time of the survey $9.6 \%$ were on parental leave. The distribution of respondents' place of employment is shown in 0 Fig. 2. 


\section{General information}

\section{Are you male or female?}

How old are you?

In which year of your specialist training in gynecology are you?

Where do you work?

- Is this the first facility for advanced training you have worked at?

If not, where did you work previously?

What is your career goal?

Physician in private practice/own practice/hospital/ teaching at a university/research/

(pharmaceuticals) industry/do not know yet/ goal which was not included in this list: (free text)

> I regularly attend the following courses: (free text)

\section{Questions on the course "Psychosomatic Primary Care"}

Have you already completed the full Psychosomatic Primary Care course?

b. Do you consider the Psychosomatic Primary Care course to be an important part of your specialist medical training?

What were the total costs of the Psychosomatic Primary Care course?

d. Where did you attend the course on psychosomatic care?

In which year of your specialist training did you start your training in psychosomatic primary care?

$1-5$, Not started yet

Are you familiar with the courses offered by the DGPFG? Yes/No

9. Were you granted time off to attend the course? Yes/No

h. Do you consider the contents of the psychosomatic care to be appropriate and useful?

Do you consider the extent of psychosomatic training to be appropriate?

If you have already attended a course on psychosomatic primary care, how satisfied were you with the course? What do you think of having "in-house training", i.e. the course is held in the facility where you receive your regular specialist training?

Should conferences in Germany include more

psychosomatic topics?

1-3, 4 = Don't care

$\mathrm{m}$. Is psychosomatics an integral part of clinical routine in your hospital?

n. Did you know that you can bill patients for psychosomatic primary care? Yes/No/Doesn't interest me.

\section{Free comments}

Fig. 1 Extract from the questionnaire collecting general information and asking questions about the course "Psychosomatic Primary Care".

The majority (56\%) of respondents reported that working in a hospital was their long-term career goal, and $15.7 \%$ of them stated that they would like a university career. $31.7 \%$ stated that their career goal was to work in their own practice, while $23.0 \%$ were still undecided about their future career path at the time of the survey, and $29.6 \%$ could imagine any one of several different places of employment. Only $2.8 \%$ hoped to work in a research setting and $0.4 \%$ in the pharmaceuticals industry.

The majority $(84.6 \%)$ regularly attended training courses which they paid for themselves.

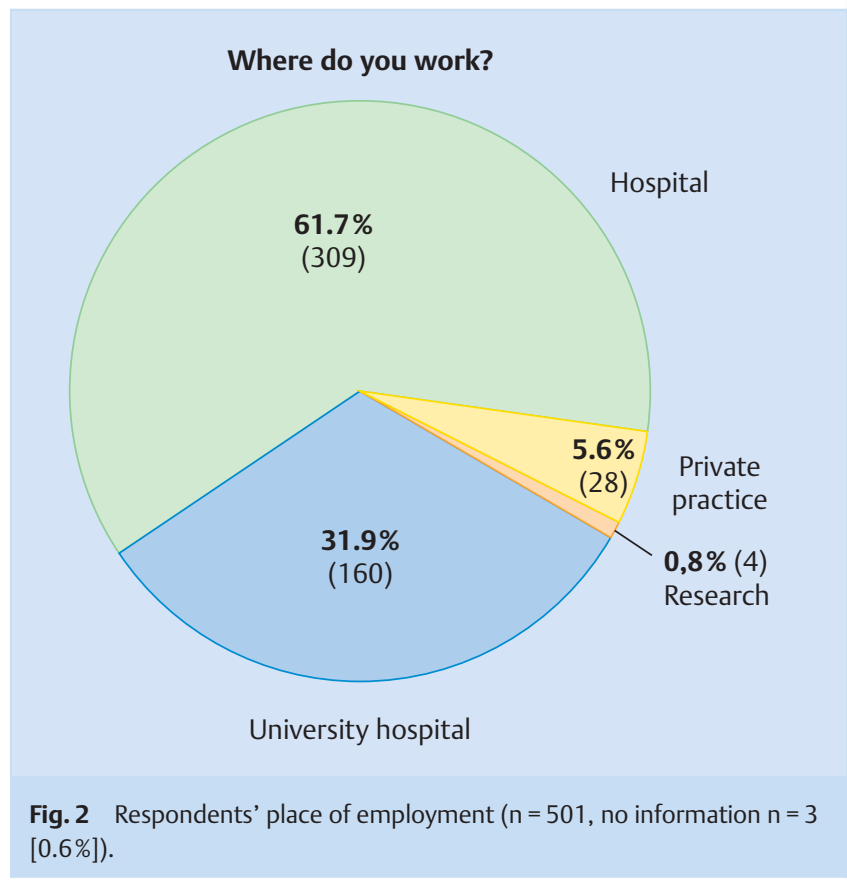

\section{General questions on the course} "Psychosomatic Primary Care"

The survey covered general information ranging from eligibility requirements to details of the course "Psychosomatic Primary Care" they had attended ( $\bullet$ Fig. 1).

The majority of respondents (70.9\%) already had some experience of the course "Psychosomatic Primary Care" and more than half of them (58.8\%) had completed the course. In general, most began attending the course in their 3rd or 4th year of training $(45.8 \%)$ without time off from their ordinary clinical duties (57.5\%).

The overwhelming majority (77\%) attended courses held in Germany; $13.8 \%$ availed themselves of in-house training courses held at the facility where they received their regular training. However, only $4 \%$ attended the course entirely free of charge. Overall, most respondents $(84.2 \%)$ welcomed the concept of inhouse training, with $42.4 \%$ describing this as an extremely good idea; only $5.1 \%$ were sceptical about it.

The average cost of a course, as reported by those who had already attended a fee-based training program, was $920 \pm 524 €$ (range: from 0 to $>2000 €$ ).

Only $8.1 \%$ of respondents had attended the courses held by the DGPFG which are specifically tailored to prospective gynecologists and obstetricians. Around $80 \%$ of the persons surveyed had never heard of the DGPFG.

\section{Experience with and evaluation of the curriculum} of the course "Psychosomatic Primary Care"

The experiences with and evaluations of the course "Psychosomatic Primary Care" were surveyed in the questions a to $n$ ( Fig. 1); they are summarized below and shown in $\bullet$ Fig. 3 .

The scope of the course was rated as $3.8 \pm 1.69$, with $41.8 \%$ of responses classified as positive compared to $51.3 \%$ of responses which were sceptical ( Fig.3a). The number of mandatory Balint group sessions received a particularly high number of adverse comments in the Comments section. The contents of the course on psychosomatic primary care were rated as average 

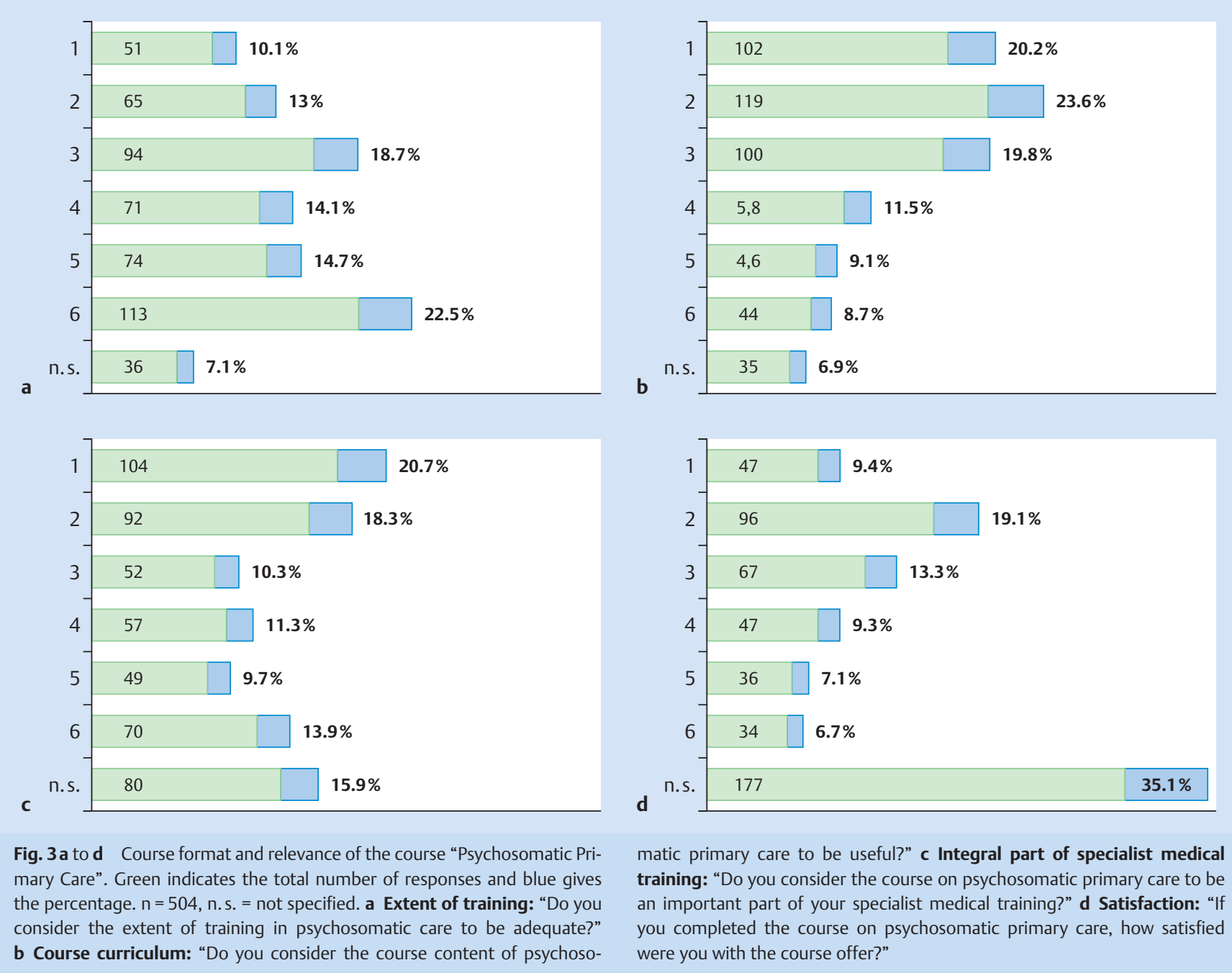

( $2.91 \pm 1.58)$ and were generally (63.6\%) endorsed; only $29.3 \%$ were not convinced by the subject matter of the course ( Fig. 3b). In the Comments section, respondents criticized the curriculum's lack of references to gynecology and obstetrics and with some stating that certain parts of the curriculum were superfluous as they treated areas already covered during medical school. The value of the course as an important part of specialist medical training was also ranked as average (3.15 \pm 1.81$)$, although positive assessments slightly predominated (49.3\%) (๑ Fig. 3c).

Overall satisfaction after completion of the course was $3.09 \pm 1.54$. More than one third $(41.8 \%)$ of respondents and $64.2 \%$ of persons who had answered this question were satisfied with the course curriculum ( Fig. $\mathbf{3 d}$ ). Respondents also attended lectures and seminars on psychosomatic topics if they were offered at conferences and the opportunities for and availability of such lectures and seminars were considered sufficient (mean: $2.6 \pm 1.01$ ). However, respondents reported that in practice psychosomatics only played a minor role in clinical routine (3.74 \pm 1.65$) .41 .5 \%$ confirmed that psychosomatics played a role in daily clinical practice; only $12.4 \%$ were of the opinion that it played a significant role, and $18 \%$ reported that it played no role in clinical practice at all.
More than half $(66.6 \%)$ of respondents knew that completion of the course was necessary to allow them to bill for this item, but only a minority (5.2\%) considered this relevant.

\section{Discussion}

$\nabla$

The view that effective, patient-centered communication must be taught and can be learned just like other medical skills has become comonplace. Many countries are aware of the special demands on effective communication between physician and patient in gynecology; the positive results reported after professional training are increasingly being noted and this type of training is being implemented in the form of recommendations by experts and mandatory additional training. In Germany, this has taken the form of the "Psychosomatic Primary Care" course, which is now part of the specialist training of gynecologists.

On the initiative of the Young Forum of the DGGG and the DGPFG an online survey was carried out to investigate the available courses on psychosomatic primary care; the aim of the survey was to investigate whether the currently available courses offer a practice-oriented curriculum in psychosomatics.

The results of the survey showed that trainees in Germany regularly attend advanced training courses in addition to their regular training. On the one hand, this reflects the overall acceptance of 
additional training and a general willingness to attend those courses. But it also raises the questions whether there may be deficiencies in certain areas of training provided by specialist medical training facilities and whether it might be necessary to search for alternative forms of training. Questions which this survey does not answer.

At present, the course "Psychosomatic Primary Care" is the only mandatory course on this topic in gynecology. The survey found that levels of satisfaction with the course varied widely among respondents. This may be due to different experiences and varying standards. The quality of the courses was not investigated in the survey, but this can be inferred based on the comments added in the Free Comments section.

In the Comments section, the limited value of psychosomatics in daily clinical practice reported by the respondents was ascribed to the currently offered courses, which had only a limited reference to gynecology and obstetrics. Other comments indicated that the course curriculum was not very relevant to clinical practice, making it difficult to apply what was learned in the course in daily practice. This criticized inability to transfer the course curriculum into clinical practice shows that the requirements for the curriculum for psychosomatic primary care, which were already formulated in 2001, have not yet been implemented properly. One suggestion for improvement proposed by respondents was the integration of course material into clinical practice. Additional proposals included in-house training, which is not very common yet. The reported limited role of psychosomatics in clinical practice is in stark contrast to studies which have shown that disease has a psychosomatic component in $20-30 \%$ of female patients treated on an outpatient basis [1]. Many studies have shown that every life-changing illness, whether it be gynecological, obstetrical or cancer-related, but also problems with menopause, sterility or chronic diseases such as endometriosis, has both a pyschological and a somatic aspect. Many clinical syndromes, for example premature labor, chronic pain in the lower abdomen or bleeding disorders, include a number of psychosocial and physical aspects during the emergence and further course of the illness, so that every physician will come into contact with psychosomatic problems during routine training and could apply psychosomatic skills.

It would be useful if physicians would learn about the diagnosis and therapy of psychosomatic syndromes early on in their specialist training as they could apply and improve what they have learned in their subsequent training; currently, however, the majority of residents only attend the course on psychosomatic care in their 3rd or 4th year of training.

Existing courses offered by the DGPFG which focus on gynecological and obstetrical aspects are not very well known. One conclusion which could be drawn from the study is that psychosomatic primary care must be considered a model of success, both in terms of how it has developed since its introduction and with regard to its empirical validation. But it must also be stated that the quality of courses on offer is very heterogenous and that they do not or only insufficiently take account of the specific requirements for psychomatic care in gynecology. This led to a joint initiative by the Young Forum of the DGGG, representatives from the DGPFG and the DAGG and from the Gynecological University Hospitals of Heidelberg and Erlangen to develop a common cur- riculum which would incorporate psychosomatic gynecological care in gynecological university hospitals. The newly drafted curriculum aims to teach practice-based state-of-the-art gynecological psychosomatics. The costs for the full course (modules 1-3) have deliberately been kept low for all of the modules. The Gynecological University Hospital Heidelberg began teaching the 1st module in March 2014. The Gynecological University Hospital Erlangen will start teaching a course in the near future. Both facilities will teach the same topics, so it should be possible to attend different modules at different university hospitals in future. Central registration for the courses is through the DAGG.

We will be reporting about the evaluation of this concept after the end of the pilot phase.

In conclusion, it can be clearly stated that psychosomatic primary care training in gynecology has an important role to play. Yet the current range of courses on offer needs to be fundamentally reformed to take account of the specific demands of gynecology and obstetrics. As a first step it will be important to develop a comprehensively reformed curriculum for psychosomatic primary care in gynecology geared to the varied demands of and working conditions in our modern healthcare system.

\section{Conflict of Interest}

\section{$\nabla$}

None.

\section{Affiliations}

${ }^{1}$ Universitätsfrauenklinik, Universitätsklinikum Heidelberg, Heidelberg

2 Department of Gynecology and Obstetrics Erlangen, University Hospital Erlangen, Erlangen

${ }^{3}$ Universitätsklinikum Charité, Medizinische Klinik mit Schwerpunkt Psychosomatik, Berlin

${ }^{4}$ Klinik für Frauenheilkunde und Geburtshilfe der Universität Regensburg am Caritas-Krankenhaus St., Regensburg

${ }^{5}$ Klinik für Allgemeine Innere Medizin und Psychosomatik, Universitätsklinikum Heidelberg, Heidelberg

${ }^{6}$ Steering Committee of the German Society for Gynecology and Obstetrics (DGGG e.V.)

${ }^{7}$ Steering Committee of the German Society for Psychosomatic Gynecology and Obstetrics (DGPFG e.V.)

${ }^{8}$ Steering Committee of the German Academy Gynecology and Obstetrics (DAGG)

\section{References}

1 Schaefert R, Hausteiner-Wiehle C, Häuser $W$ et al. Nicht-spezifische, funktionelle und somatoforme Körperbeschwerden. Dtsch Arztebl International 2012; 109: 803-813

2 Kassenärztliche-Bundesvereinigung. Einheitlicher Bewertungsmaßstab. Köln: Deutscher-Ärzteverlag; 2013: 689-690

3 Bundesärztekammer. Curriculum Psychosomatische Grundversorgung - Basisdiagnostik und Basisversorgung bei Patienten mit psychischen und psychosomatischen Störungen einschließlich Aspekte der Qualitätssicherung. In: Texte und Materialien der Bundesärztekammer zur Fortbildung und Weiterbildung. 2. Auflage. ISBN 0945-1951

4 Tress W, Kruse J, Heckrath C et al. Psychosomatische Grundversorgung in der Praxis: Erhebliche Anforderungen an niedergelassene Ärzte. Dtsch Arztebl International 1996; 93: 597

5 Lermann J, Schott S, Dörr A et al. Eine Erweiterung zu Geburtsh Frauenheilk 2011; 71: 312-313. Ist eine Weiterbildung in Kursform „Psychosomatische Grundversorgung in der Frauenheilkunde“ zwingend notwendig? Geburtsh Frauenheilk 2011; 71: 550-551

6 Siedentopf F, Rauchfuß M, Kentenich H. Ist eine Weiterbildung „Psychosomatische Grundversorgung in der Frauenheilkunde“ zwingend notwendig? Geburtsh Frauenheilk 2011; 71: 312-313 